\title{
Glutathione ameliorates Hypoxia/Reoxygenation (H/R) induced hepatocyte oxidative damage via regulating $\mathrm{HO}-1$ signaling
}

\author{
Wuye CHEN ${ }^{1}$, Kunping $\mathrm{LI}^{1}$, Shaomei ZHU², Xiaozai $\mathrm{LUO}^{1}$, Yihong WANG ${ }^{1}$, Zhengyu LIU ${ }^{1}$, Yongping FANG ${ }^{1 *}$ (D), \\ Zhengyuan XIA ${ }^{3 *}$
}

\begin{abstract}
In our study, CCK-8 assay and LDH release detection were performed to detect the optimal protective concentration of GSH on HL7702 cell viability during H/R injury. HL7702 cells were randomly divided into four groups: Control group, H/R group, $\mathrm{H} / \mathrm{R}+\mathrm{GSH}$ group, and $\mathrm{H} / \mathrm{R}+\mathrm{GSH}+\mathrm{HO}-1$-siRNA group. Then, reactive oxygen species (ROS) was evaluated by DHE staning, MDA, T-SOD measurements; Cell injury was detected by CCK-8, LDH release, and supernatant AST and ALT levels; Apoptosis was determined by Hoechst staining and caspase 3 level. Compared with controls, H/R caused significant HL7702 cell injury evidenced as reduced cell viability, increased LDH release and apoptotic cell death $(P<0.01)$, with concomitant increases in ROS and MDA production $(P<0.01)$, while treated with GSH in $\mathrm{H} / \mathrm{R}$ group significantly attenuated oxidative injury, enhanced cell viability and downregulated cell apoptosis $(P<0.01)$ together with HO-1 upregulation $(P<0.01)$. Knockdown HO-1 by its siRNA cancelled the protective effects of GSH from H/R compared with GSH group $(\mathrm{P}<0.01)$. HO- 1 was induced in HL7702 exposed to $\mathrm{H} / \mathrm{R}$ injury and its level was obviously overexpressed after $\mathrm{H} / \mathrm{R}$ injury with GSH treatment, suggesting its protective potential in GSH against H/R injury. GSH increases the expression of HO-1, which enhanced the early antioxidative activity and played a protective role against HL7702 cells H/R injury.
\end{abstract}

Keywords: glutathione; hepatocellular; hypoxia/reoxygenation injury; HO-1.

Practical Application: GSH might be a novel agent to improve the clinical treatment of H/R-induced liver impairments.

\section{Introduction}

Ischemia/reperfusion $(\mathrm{I} / \mathrm{R})$ injury may occur in various organs, which is a common clinical problem. Although the pathophysiological mechanisms underlying I/R or hypoxia/ reoxygenation $(H / R)$ injury are unclear, oxidative damage is considered a key factor in the initiation of I/R injury (Li et al., 2018). Liver is sensitive to ischemia and hypoxia, thus, how to effectively relieve postoperative hepatic ischemia-reperfusion injury (HIRI) has become a hot topic in clinical research (Pagano et al., 2018; Rakić et al., 2018). The formation of reactive oxygen species (ROS) and pro-inflammatory cytokines, as well as oxidative stress, are thought to be the main mechanisms leading to HIRI. The molecular mechanisms mediating hepatocellular $\mathrm{H} / \mathrm{R}$ injury are largely unknown, however, activation of cell apoptosis play an important role in its pathology (Ge et al., 2019; Katwal et al., 2018). Apoptosis, a process of programmed cell death, significantly contributes to both hepatocellular loss during liver I/R injury and liver failure after ischemia (Gao et al., 2018). Animal studies have demonstrated that antioxidants can improve HIRI injury by increasing expression of antioxidant enzymes, and increasing antioxidant capacity during early phase of I/R may be a potential therapeutic approach to reduce the incidence of HIRI and hepatic fibrosis.
Heme Oxygenase-1 (HO-1), also known as heat shock protein 32 , is mainly distributed in the tissues and organs of haemocytes that are actively metabolized, such as liver, spleen and bone marrow, and plays a key role as an important antioxidant enzyme. When the body is subjected to oxidative stress, $\mathrm{HO}-1$ expression is enhanced to strengthen the antioxidant capacity of the body (Ge et al., 2017b; Luo et al., 2020; Wang et al., 2020). This protection is primarily achieved by reducing ROS formation, stabilizing cell membranes, and reducing cell apoptosis in the early stage of HIRI. It is the main mechanism of body self-protection during oxidative stress (Gao et al., 2015; Ge et al., 2017a; Ma et al., 2015).

As an antioxidant, GSH has been widely used for the treatment of liver damage caused by viral infection, drug toxicity, alcohol toxicity and other chemical toxicity, but it is rarely used in hepatic ischemia-reperfusion injury in clinic (Moss et al., 2018; Xu et al., 2018; Zhang et al., 2009). The main function of G SH is to eliminate oxidation products in the late HIRI, which seems to have little effect in the early stage of the disease, and thus application of GSH was rare during acute liver injury. Many drugs, such as curcumin, Swertiamarin and Tanshinol have been shown not only promote GSH synthesis in vivo but also activate the $\mathrm{HO}-1$ pathway in oxidative stress 
process. However, there are few studies on whether there is a relationship between the increase of GSH and the activation of HO-1 pathway during oxidative stress and in particular during liver I/R. Thus, this study was aimed to investigate the beneficial effects and its underlying mechanism of GSH on hepatocyte during $\mathrm{H} / \mathrm{R}$ injury.

\section{Materials and methods}

\subsection{Cell culture}

Human hepatocyte HL7702 was purchased from Cellbank corporation (ShangHai, China). HL7702 cells $\left(2^{\star} 10^{6}\right.$ cells per well in six well tissue culture plate) were cultured in an incubator (Esco, Singapore) with $4.5 \mathrm{~g} / \mathrm{L}$ DMEM (Thermo Fisher Scientific, USA) $+10 \%$ fetal bovine serum (FBS) (Thermo Fisher Scientific, USA) +100 units $/ \mathrm{mL}$ penicillin and $100 \mathrm{mg} / \mathrm{mL}$ streptomycin (Thermo Fisher Scientific, USA) under the condition of $37^{\circ} \mathrm{C}$ $5 \% \mathrm{CO}_{2}$ and $95 \% \mathrm{O}_{2}$.

\subsection{HL7702 Cells Hypoxia/Reoxygenation (H/R) model}

Hypoxic environment was a moist and closed plastic vessel (Billups Rothenberg, Inc., Del Mar, CA). Replaced with sugar-free medium, then cells were placed onto the hypoxic vessel, filled with the mixture of $94 \% \mathrm{~N}_{2}, 5 \% \mathrm{CO}_{2}$ and $1 \% \mathrm{O}_{2}$ for 15 minutes ( $\mathrm{min}$ ), and subjected to hypoxia for 6 hours under $37^{\circ} \mathrm{C}$. Replaced the medium (DMEM $+10 \%$ fetal bovine serum (FBS) (Gibco, Thermo Fisher Scientific, USA) +100 units/mL penicillin and $100 \mathrm{mg} / \mathrm{mL}$ streptomycin (Thermo Fisher Scientific, USA), reoxygenated for $4 \mathrm{~h}$ by exposing the cells to a cell incubator (Esco, Singapore). The cells were assigned to the following groups: Control (C) group, which did not undergo H/R and were cultured in the normal sugar medium; $\mathrm{H} / \mathrm{R}$ group, which with 6-hour and 4-hour reoxygenation; GSH group, with the same treatment as the $\mathrm{I} / \mathrm{R}$ group but added GSH $(20 \mathrm{mmol} / \mathrm{L})$ before $\mathrm{H} / \mathrm{R}$ injury; $\mathrm{HO}-1$ siRNA group, treated the same as the GSH group but with 24 hours HO-1siRNA transfection before the $\mathrm{H} / \mathrm{R}$ injury.

\subsection{GSH's optimal protection concentration}

HL7702 cells were planted in 96 well plates (Corning, USA) at a density of 6000 cells/well. Before H/R injury, cells were treat with different concentrations of GSH (Beyotime, China) (0, 5, 10, 20, 40, 80 and $160 \mathrm{mmol} / \mathrm{L})$. After 6-hour hypoxia and 4-hour reoxygen, $10 \mu \mathrm{l} /$ well of Cell Counting Kit-8 (Dojindo, Japan) were added and incubated with the cells at $37^{\circ} \mathrm{C}$ for $2 \mathrm{~h}$, a microplate reader (REAGEN, USA) was used to measure optical densities at $450 \mathrm{~nm}$. LDH release was detected by Cytotoxicity Detection Kit (Thermo Fisher Scientific, USA) as described in the instructions.

\subsection{HO-1 small interfering RNA transfection model}

HL7702 cells were transfected with human HO-1 siRNA (Santa Cruz Biotechnology, USA). Briefly, cells were trypsinized and plated on 6 -well plates at $50 \%$ to $60 \%$ confluence $24 \mathrm{~h}$ before transfection. HO-1 siRNA ( $50 \mathrm{nmol} / \mathrm{L})$, transfection medium and reagent were mixed and incubated at room temperature for
40 min. HO- 1 siRNA-reagent complexes were added and the medium was replaced with general medium after transfection for $6 \mathrm{~h}$. Experiments were performed $24 \mathrm{~h}$ after transfection. The changes of HO-1 protein expression was analyzed by Western blot.

\subsection{DAPI staining and Dihydroethidium (DHE) fluorescence}

After 4\% paraformaldehyde fixation, HL7702 cells were incubated with DAPI (Solarbio, China) for $10 \mathrm{~min}$ and DHE (YEASEN, China) for $15 \mathrm{~min}$ at $37^{\circ} \mathrm{C}$ respectively and then rinsed twice in PBS for nuclear staining and reactive oxygen species (ROS) detection. A fluorescence microscope (Olympus, Japan) was used to observe DAPI and DHE fluorescence. The number of positive cells marked with DHE staining per $\mathrm{mm}^{2}$ was counted in each group.

\subsection{Hoechst 33258 staining}

HL7702 cells were seeded into 24 -well plates at a density of $5 \times 10^{4}$ cells $/ \mathrm{ml}$ in $1 \mathrm{ml}$ volumes and then incubated for 24hous under a humidified atmosphere of $5 \% \mathrm{CO} 2$ at $37^{\circ} \mathrm{C}$. After incubated with DMEM (Thermo Fisher Scientific, USA) containing $5.5 \mathrm{mmol} / \mathrm{L}$ glucose for $48 \mathrm{~h}$, cells were rinsed twice in PBS (Life Technologies, Thermo Fisher Scientific, USA) for $5 \mathrm{~min}$ and then fixed with $4 \%$ paraformaldehyde (YEASEN, China) for $15 \mathrm{~min}$ at room temperature (RT). After washed twice in PBS for $5 \mathrm{~min}$, cells were incubated with $0.5 \mu \mathrm{g} / \mathrm{ml}$ Hoechst 33258 (Beyotime, China) solution in the dark for 5 min at RT. Finally, the cells were washed twice with PBS and were observed under a fluorescence microscope (Olympus, Japan).

\subsection{ELISA kit assay}

The level of superoxide radical were determined by MDA and T-SOD ELISA kit (JIANGLAI, China) as the respective manufacturers' protocols. The liver cell levels of ALT and AST were detected by ELISA kit (JIANGLAI, China) as the respective manufacturers' protocols.

\subsection{Western blot analysis}

After treatment, cells were washed with PBS, lysed in RIPA buffer (Sigma-Aldrich) containing 1\% protease inhibitor cocktail and $1 \%$ of the phosphatase inhibitor cocktails 2 and 3 (SigmaAldrich), and then solubilized proteins were collected after centrifugation at $13,000 \times \mathrm{g}$ for $15 \mathrm{~min}$ at $4{ }^{\circ} \mathrm{C}$ and stored at $-80^{\circ} \mathrm{C}$. The protein concentration of each sample was measured by using the enhanced BCA Protein Assay kit (Thermo Scientific, USA) with bovine serum albumin (BSA) as a standard. Thereafter, an equal volume of protein sample and sample buffer was mixed and the samples were boiled for $12 \mathrm{~min}$ at $100{ }^{\circ} \mathrm{C}$. To detect the changes of HO-1, caspase- 3 and GAPDH, protein lysates from each group of cells were separated by SDS-PAGE and electrotransferred onto a PVDF membrane (Millipore, Frankfurt, Germany). After blocking with 3\% BSA in TBST with $10 \mathrm{mM}$ Tris-HCl, $250 \mathrm{mM} \mathrm{NaCl}$, and $0.05 \%$ Tween 20 (pH 7.5) for 2 hour, the membranes were probed with the primary antibodies against HO-1, caspase-3 and GAPDH (1:1000) (Cell Signaling 
Technology, Danvers, USA) overnight at $4{ }^{\circ} \mathrm{C}$, The membranes were washed thoroughly for $3 \times 15$ minutes with TBST and then probed with secondary IgG antibodies (Cell Signaling Technology, Danvers, USA) at a 1:5000 dilution in the shaker at RT for 2 hous, and then washed with TTBS three times each for $15 \mathrm{~min}$. Finally, the immunoreactive bands were detected by an ECL kit (Beyotime, China) and visualized after exposure to X-ray film (Beyotime, China). The volume of the protein bands was quantified using a Bio-Rad Chemi EQ densitometer and Bio-Rad Quantity One software (Bio-Rad laboratories, Hercules, CA, USA). The ratios of HO- 1 , caspase- 3 to GAPDH were then determined.

\subsection{Statistical analysis}

Each experiment was performed in duplicate or triplicate and was repeated at least three times. All quantitative data are expressed as mean \pm the standard error of the mean \pm S. E. M. All statistical tests were performed with the Prism software (GraphPad Prism, San Diego, USA). One-way ANOVA test was used to determine significant differences within group and between groups, respectively, followed by Tukey's test for multiple comparisons of group means. $P<0.05$ was accepted as statistically significant.

\section{Results}

\subsection{Effect of different concentrations of GSH on cell viability and LDH release in $\mathrm{HL7702}$ cells}

Whether GSH has protective effect on hypoxic-reoxygenated liver cells and the optimal concentration is the first question to be answered in the experiment. Comparing with non-treated cells, $5 \mu \mathrm{mol} / \mathrm{L}$ concentration of GSH began to protect the hypoxic-reoxygenated hepatocytes, manifested by increased cell viability and decreased LDH release (Figure $1 \mathrm{~A}$ and $\mathrm{B}, P<0.01$ ). As the concentration increased, the protective effect gradually increased; when the concentration reached $20 \mu \mathrm{mol}$, hepatocyte damage was minimal. As the concentration continued to increase, the protective effect did not further and even be weakened. The effect of GSH and HO-1 siRNA on HO-1 expression in hypoxic-reoxygenated liver cells is the key to the experiment. The results of western blot assay showed that the expression of HO-1 in $\mathrm{H} / \mathrm{R}$ hepatocytes could be regulated by GSH or HO-1 siRNA. Comparing with H/R group, the treatment of GSH
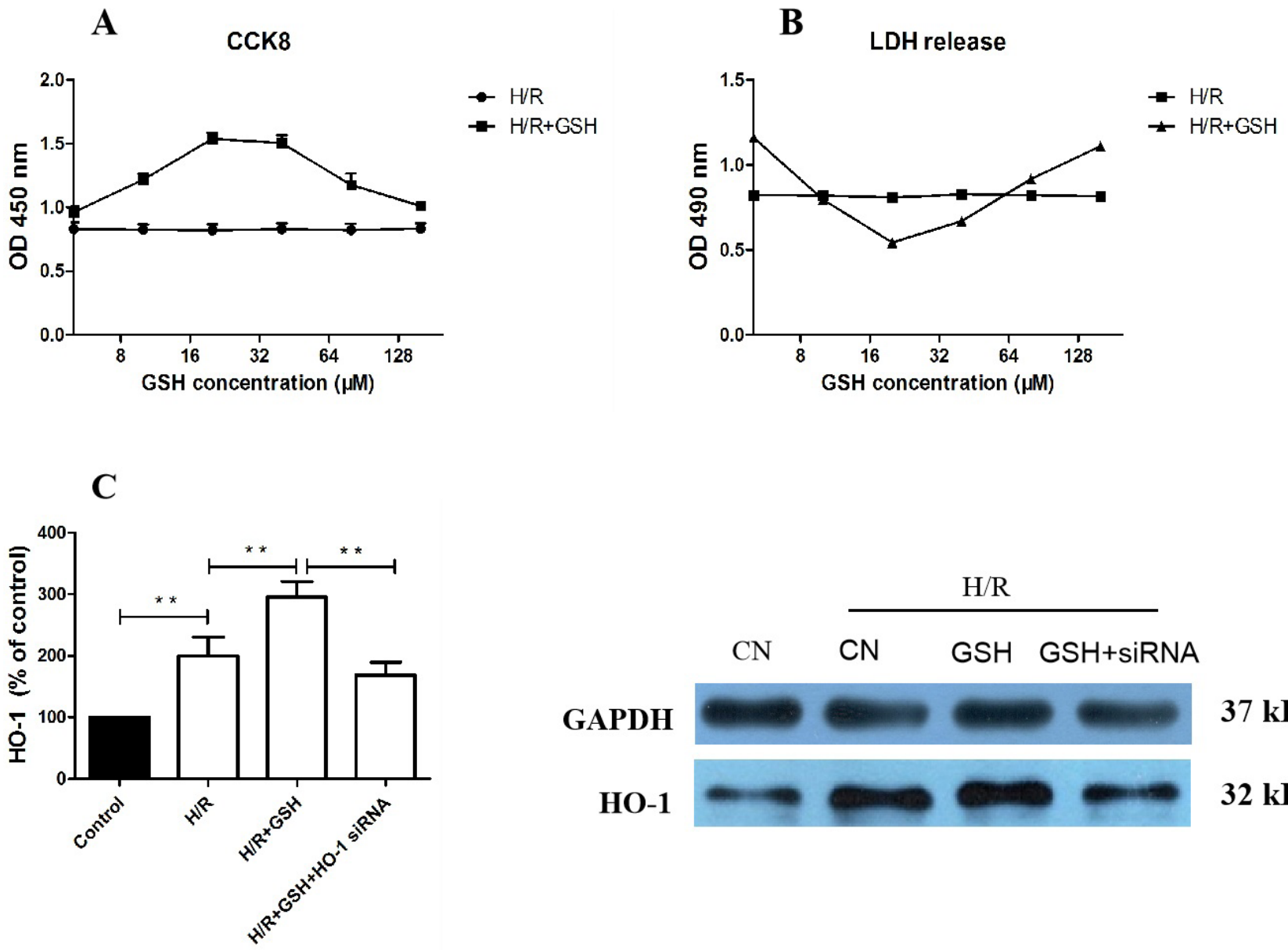

GAPDH

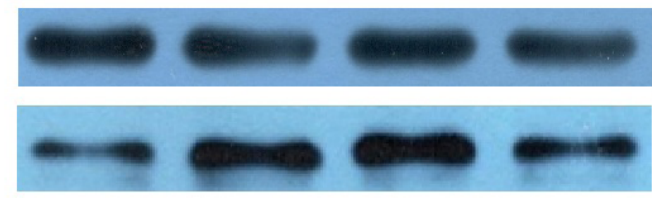

37 kDa

HO-1

32 kDa

Figure 1. Effects of various contractions of GSH on H/R induced cell injury. (A, B) By administrating different concentrations of GSH before H/R, we found that GSH at $20 \mu \mathrm{mol} / \mathrm{L}$ was the most suitable protective concentration as reflected in the results of CCK- 8 and LDH release analyses. (C) The expression of HO-1 was detected by western blot. Results are presented as mean \pm S. E. M., $\mathrm{n}=6,{ }^{* \star} P<0.01$. 
in the early stage of $\mathrm{H} / \mathrm{R}$ significantly enhanced the expression of antioxidant enzyme HO-1, and such effect of GSH was weakened or even disappeared in hepatocyte transfected with HO-1 siRNA (Figure 1C, $P<0.01$ ).

\subsection{GSH reduced the production of ROS in $\mathrm{HL7702}$ cells H/R injury}

DHE staining combined with DAPI staining were applied to monitor intracellular ROS. Excessive ROS can further increase the production of MDA, one of the important products of membrane lipid peroxidation, which can aggravate membrane damage (Hu et al., 2020). Superoxide dismutase is an antioxidant metal enzyme that exists in the body. It can remove excess ROS and plays a vital role in the body's oxidation and antioxidant balance. Compared with controls, ROS production as reflected by intensity of DHE staining and MDA production were significantly increased in cells subjected to $\mathrm{H} / \mathrm{R}$ (Figure $2 \mathrm{~A}$ and $\mathrm{B}, P<0.01$ ), and early addition of GSH to cell before inducing $\mathrm{H} / \mathrm{R}$ significantly reduced the excessive production of ROS, thereby reducing the production of MDA and cell membrane damage; this protective effect was weakened after HO-1siRNA transfection compared with GSH-treated $\mathrm{H} / \mathrm{R}$ cells. $\mathrm{H} / \mathrm{R}$ resulted in significant reduction of SOD activity, which was reversed by GSH treatment (Figure 2C, $P<0.01)$. However, GSH mediated restoration of post-hypoxic SOD activity was abolished by HO-1siRNA transfection.

\subsection{GSH enhanced liver cell membrane stability and improves cell viability after $\mathrm{H} / \mathrm{R}$ injury through $\mathrm{HO}-1$ signaling.}

We assessed the effects of H/R injury and GSH therapy on the viability of HL7702 cells. The CCK8 assay was used for cell viability assay, and the supernatant LDH, AST and ALT assay was used to detect the degree of cell membrane damage. The results showed that compared with H/R group, GSH treatment in the early stage significantly enhanced the viability of liver cells and the destruction of cell membranes, which is shown by the increase of CCK8 readings and the decrease of $\mathrm{LDH}$ release (Figure $3 \mathrm{~A}$ and $\mathrm{B}, P<0.01$ ). However, the protective effects of
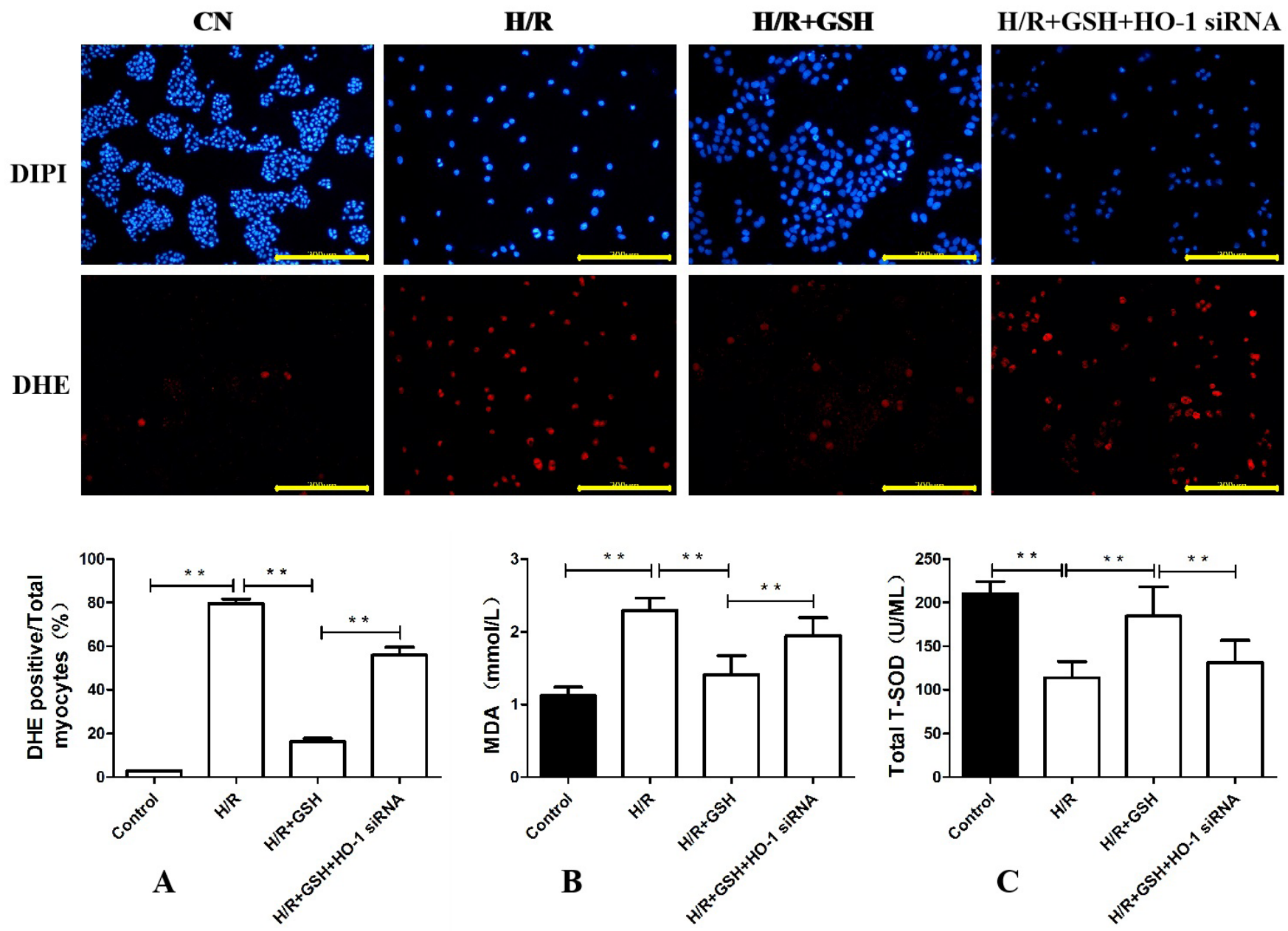

Figure 2. GSH reduced the production of ROS induced by H/R injury in HL7702 cells. (A) DHE staining showed that H/R injury led to more production of ROS, and reduced by GSH. While when HO-1 expression was reduced by siRNA transfection, though H/R group was treated with GSH, a over production of ROS was still observed. The length of yellow line segment in the figure indicates $200 \mu \mathrm{m}$. All images are at $\times 200$ magnification. (B, C) The changes of plasma MDA and T-SOD were detected by ELISA kit assays. All the results are presented as mean \pm S. E. M. $(n=6),{ }^{* *} \mathrm{P}<0.01$. 
GSH decreased sharply or were diminished when HO-1 was silenced (Figure $3 \mathrm{~A}$ and $\mathrm{B}, P<0.01$ ).

\subsection{GSH enhanced the expression of HO-1 against hepatic $H / R$ injury by reducing apoptosis}

HO-1 enhanced the ability of early hepatocytes to resist oxidative stress by reducing cell apoptosis. Hoechst 33258 staining (Figure 4A, $P<0.01$ ) and western blot (Figure $4 \mathrm{~B}, P<0.01$ ) showed that compared with H/R group, GSH significantly reduced hepatocyte apoptosis and H/R injury. However, the protective effects of GSH was negated if we inhibiting the expression of HO-1. The red arrows indicate apoptotic cells as shown in the blow figure.

\section{Discussion}

Hepatic ischemia-reperfusion (I/R) injury is a common cause of organ dysfunction in clinical liver transplantation, mainly involving inflammation and apoptosis (Chen et al., 2021; Moss et al., 2018; von Platen et al., 2021). Development of H/R is associated with metabolic acidosis, calcium overloading, and changes of mitochondrial membrane permeability. Hypoxia-induced
A
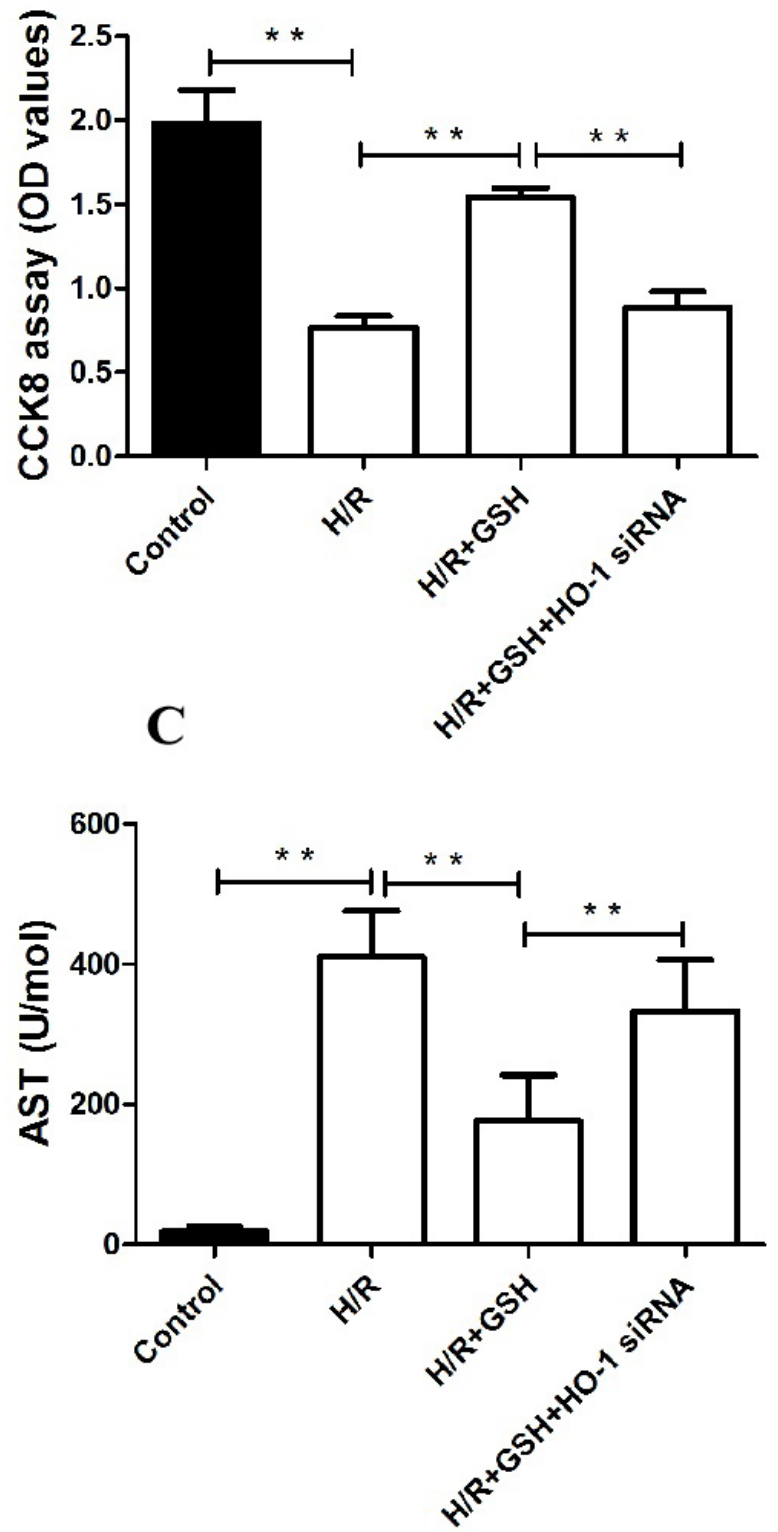

B
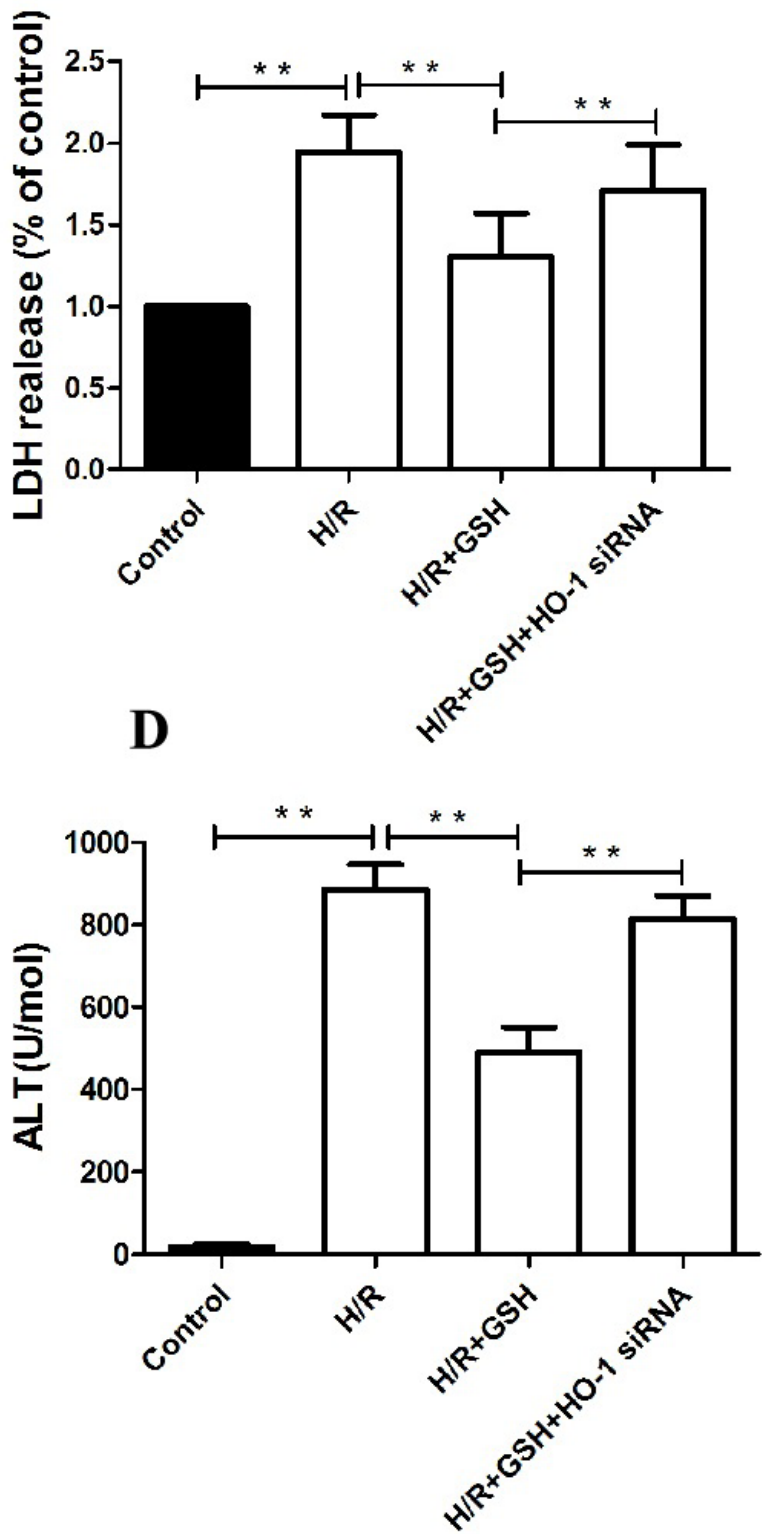

Figure 3. H/R injury disrupts cell membrane stability and reduced the cell viability which manifests as increased release of LDH (B), AST (C) and ALT (D). GSH significantly protected HL7702 cells from H/R injury by enhancing liver cell membrane stability and improves cell viability (A). However, the protective effects of GSH was negated if we inhibiting the expression of HO-1. Results are presented as mean \pm S. E. M. $(n=6)$, ${ }^{*} P<0.01$. 
$\mathbf{A}$

CN

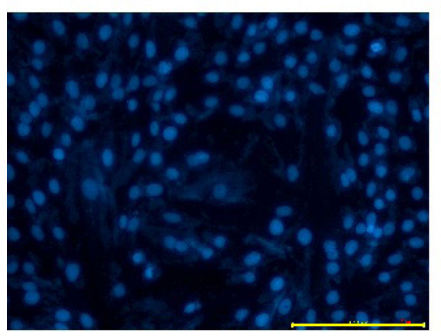

$\mathbf{H} / \mathbf{R}$

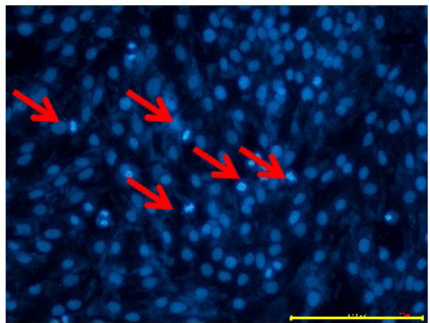

H/R+GSH

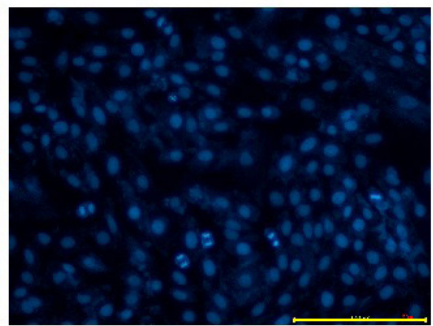

\section{H/R+GSH+HO-1 siRNA}

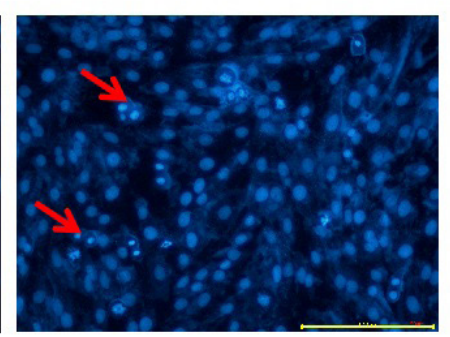

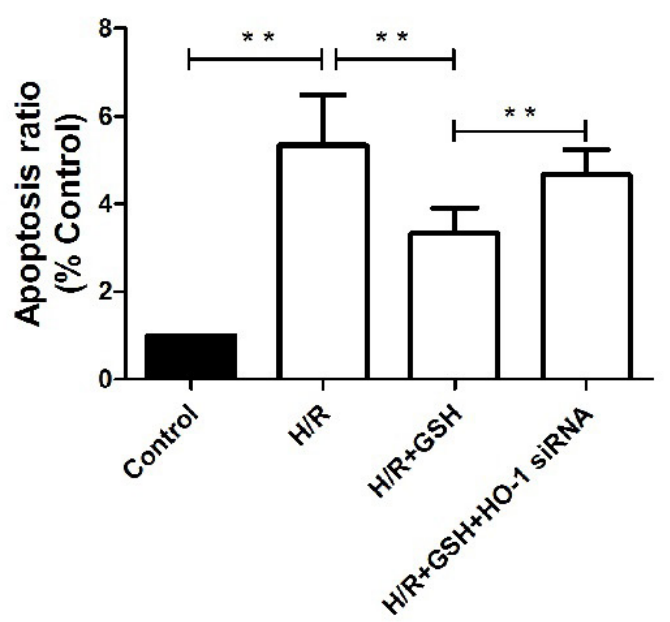

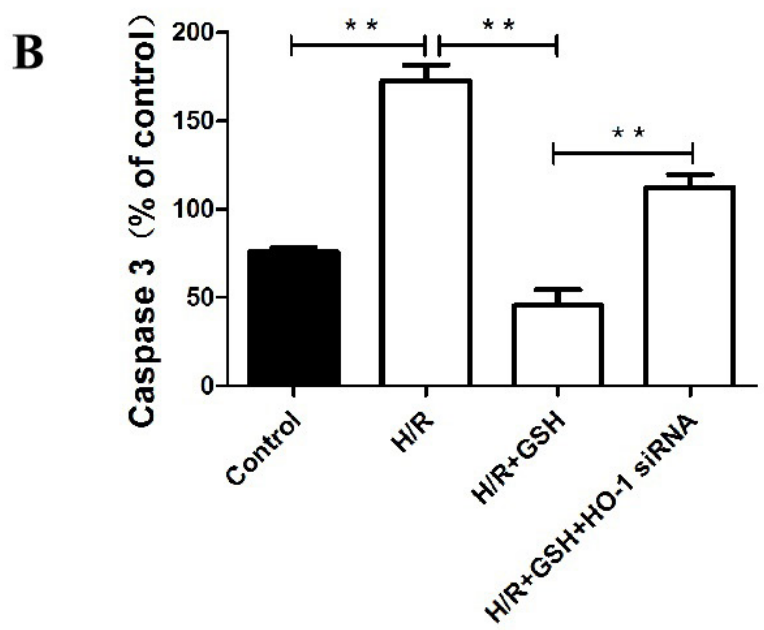

GAPDH

Caspase 3
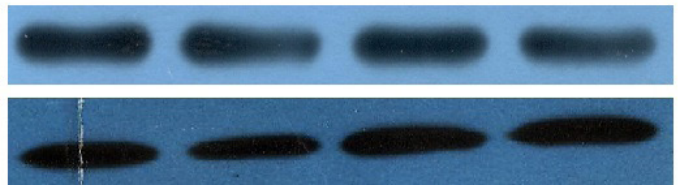

\section{7 kDa}

\section{5 kDa}

Figure 4. Hoechst staining (A) showed that GSH can reduce the apoptosis of HL7702 cells in the early stage of oxidative stress injury, and western blot showed that this protective effect was related to the decreased expression of caspase3 (B); Similar to our previous results, this protective effect was reduced by regulating the reduction of HO-1 expression. Results are presented as mean $\pm \mathrm{S}$. E. M. $(\mathrm{n}=6)$. The length of yellow line segment in the figure indicates $200 \mu \mathrm{m}$. All images are at $\times 200$ magnification. ${ }^{* *} P<0.01$.

activation of Kupffer cells results in generation of reactive oxygen species (ROS) (Cannistrà et al., 2016; Peralta et al., 2013). These processes lead to the activation of inflammation and immune responses, related with multiple cells and signaling molecules, and eventually result in increased level of apoptosis and necrosis (Fu et al., 2019). Current pharmocological research on reducing liver ischemia-reperfusion injury is mainly focused on some Chinese herbal medicines, including whether the concerned drugs could clear ROS or reduce apoptosis. However, further studies on the investigation of effective drugs or components against $\mathrm{H} / \mathrm{R}$-induced liver injury are still in an urgent request.

In the past, GSH was generally considered to protect the late stage of oxidative damage by removing oxidative stress products and stabilizing cell membranes. GSH does not seem to enhance the anti-oxidative stress of hepatocytes in the early stage. Thus, to determine the protective effects of GSH on liver cells in the early stages of oxidative stress still remains further clarifications.
Recently, studies on the treatment of hepatic H/R injury have been focused on drugs. Many drugs have been shown to not only increase the GSH content in the body, but also enhance the expression of HO-1, thereby protecting the liver. Whether there is any kind of interaction between the two is not a clinical hot spot. Interestingly, the protective effect of GSH on hepatocytes in this study was always accompanied by an increase in the expression of HO-1. The protective effect of GSH disappeared when HO-1 expression was reduced by gene silencing, and there was an interaction relationship between GSH and HO-1. In summary, HL7702 cells treatment with GSH $(20 \mathrm{mmol} / \mathrm{L})$ increases the expression of $\mathrm{HO}-1, \mathrm{HO}-1$ enhanced the antioxidative activity and played a protective role against cells $\mathrm{H} / \mathrm{R}$ injury. The protective effects of GSH were significantly associated with greater intrahepatic HO-1 expression. Thus, it can be concluded that GSH alleviates hepatocellular H/R injury through activating the HO-1 pathway. Future study is merited to 
further verify the relationship between GSH and HO-1 through in vivo animal model of hepatic $\mathrm{H} / \mathrm{R}$ injury, which shall greatly promote the application of GSH in hepatic ischemia-reperfusion injury, while avoiding abandoning GSH and HO-1.

In this regard, we believe that the key to reducing liver ischemia-reperfusion injury is to improve the anti-oxidative capacity of liver cells in the early stage ischemic insult. The protective effect of HO-1 in the early stage of hypoxia-reperfusion injury is relatively clear, and the problem that needs to be solved is to find drugs that can enhance the expression of $\mathrm{HO}-1$ at an early stage. Based on these theories, our study was designed to determine the protective effect of GSH on liver cells, and clarified whether HO-1 upregulation in the early stage underlies its beneficial potential. We observed that the damage of hepatocytes by hypoxiareoxygenation was mainly as follows: Firstly, a large amount of ROS was formed in the early stage of reoxygenation which promoted the further inflammation development, and MDA was increased and SOD was consumed. Secondly, the cell membrane is destroyed, then the cell viability decreased and ALT, AST were released from hepatocytes. Thirdly, Hepatocellular inflammation progresses further and early apoptosis increases. Meaningfully, We demonstrated that administration of GSH before H/R enhanced the early antioxidant capacity of hepatocytes, and the optimal concentration of GSH is $20 \mu \mathrm{mol} / \mathrm{L}$. The protective effect of GSH on H/R hepatocytes is mainly reflected in the following aspects: 1) GSH reduced the formation of ROS in early stage of reoxygenation to prevented further development of inflammation. 2) It increased cell viability and decreased the release of Stable cell membrane. 3) It reduced apoptosis and prevented further inflammation. Thus, our discovery initially demonstrated the beneficial effects of GSH on H/R-impaired liver cells, as well as the determination of its underlying mechanism by regulating HO- 1 expression and apoptosis, providing a potential strategy against H/R-induced ROS overload or apoptosis.

\section{Conclusions}

The results demonstrate that GSH alleviates H/R injury of liver cells apoptosis through regulating the expression of HO-1. The findings strengthen the idea that GSH might be a novel agent to improve the clinical treatment of $\mathrm{H} / \mathrm{R}$-induced liver impairments.

\section{Funding}

This work was supported by the National Natural Science Foundation of China [grant number 81801997].

\section{References}

Cannistrà, M., Ruggiero, M., Zullo, A., Gallelli, G., Serafini, S., Maria, M., Naso, A., Grande, R., Serra, R., \& Nardo, B. (2016). Hepatic ischemia reperfusion injury: a systematic review of literature and the role of current drugs and biomarkers. International Journal of Surgery, 33(Suppl 1), S57-S70. http://dx.doi.org/10.1016/j.ijsu.2016.05.050. PMid:27255130.

Chen, S. Y., Zhang, H. P., Li, J., Shi, J. H., Tang, H. W., Zhang, Y., Zhang, J. K., Wen, P. H., Wang, Z. H., Shi, X. Y., He, Y. T., Hu, B. W., Yang, H., Guo, W. Z., \& Zhang, S. J. (2021). Tripartite Motif-Containing 27 attenuates liver ischemia/reperfusion injury by suppressing transforming growth factor $\beta$-Activated Kinase 1 (TAK1) by TAK1 binding protein $2 / 3$ degradation. Hepatology (Baltimore, $M d$.), 73(2), 738-758. http://dx.doi.org/10.1002/hep.31295. PMid:32343849.

Fu, Z., Fan, Q., Zhou, Y., Zhao, Y., \& He, Z. (2019). Elimination of intracellular calcium overload by BAPTA-AM-loaded liposomes: a promising therapeutic agent for acute liver failure. ACS Applied Materials \& Interfaces, 11(43), 39574-39585. http://dx.doi.org/10.1021/ acsami.9b13690. PMid:31589019.

Gao, S., Wang, Y., Zhao, J., \& Su, A. (2015). Effects of dexmedetomidine pretreatment on heme oxygenase- 1 expression and oxidative stress during one-lung ventilation. International Journal of Clinical and Experimental Pathology, 8(3), 3144-3149. PMid:26045831.

Gao, Y., Zhou, S., Wang, F., Zhou, Y., Sheng, S., Qi, D., Huang, J. H., Wu, E., Lv, Y., \& Huo, X. (2018). Hepatoprotective effects of limb ischemic post-conditioning in hepatic ischemic rat model and liver cancer patients via PI3K/ERK pathways. International Journal of Biological Sciences, 14(14), 2037-2050. http://dx.doi.org/10.7150/ ijbs.28435. PMid:30585267.

Ge, L., Cai, Y., Ying, F., Liu, H., Zhang, D., He, Y., Pang, L., Yan, D., Xu, A., Ma, H., \& Xia, Z. (2019). miR-181c-5p exacerbates hypoxia/ reoxygenation-induced cardiomyocyte apoptosis via targeting PTPN4. Oxidative Medicine and Cellular Longevity, 2019, 1957920. http:// dx.doi.org/10.1155/2019/1957920. PMid:31178952.

Ge, M., Chen, H., Zhu, Q., Cai, J., Chen, C., Yuan, D., Jin, Y., Yao, W., \& Hei, Z. (2017a). Propofol post-conditioning alleviates hepatic ischaemia reperfusion injury via BRG1-mediated Nrf2/HO-1 transcriptional activation in human and mice. Journal of Cellular and Molecular Medicine, 21(12), 3693-3704. http://dx.doi.org/10.1111/ jcmm.13279. PMid:28749008.

Ge, M., Yao, W., Yuan, D., Zhou, S., Chen, X., Zhang, Y., Li, H., Xia, Z., \& Hei, Z. (2017b). Brg1-mediated Nrf2/HO-1 pathway activation alleviates hepatic ischemia-reperfusion injury. Cell Death \& Disease, 8(6), e2841. http://dx.doi.org/10.1038/cddis.2017.236. PMid:28569786.

Hu, Y., Liu, S., \& Zhu, B. M. (2020). CRISPR/Cas9-Induced Loss of Keap1 enhances anti-oxidation in rat adipose-derived mesenchymal stem cells. Frontiers in Neurology, 10, 1311. http://dx.doi.org/10.3389/ fneur.2019.01311. PMid:32132961.

Katwal, G., Baral, D., Fan, X., Weiyang, H., Zhang, X., Ling, L., Xiong, Y., Ye, Q., \& Wang, Y. (2018). SIRT3 a major player in attenuation of hepatic ischemia-reperfusion injury by reducing ros via its downstream mediators: SOD2, CYP-D, and HIF-1a. Oxidative Medicine and Cellular Longevity, 2018, 2976957. http://dx.doi. org/10.1155/2018/2976957. PMid:30538800.

Li, H., Xia, Z., Chen, Y., Qi, D., \& Zheng, H. (2018). Mechanism and therapies of oxidative stress-mediated cell death in ischemia reperfusion injury. Oxidative Medicine and Cellular Longevity, 2018, 2910643. http://dx.doi.org/10.1155/2018/2910643. PMid:30034574.

Luo, J., Yan, D., Li, S., Liu, S., Zeng, F., Cheung, C. W., Liu, H., Irwin, M. G., Huang, H., \& Xia, Z. (2020). Allopurinol reduces oxidative stress and activates Nrf2/p62 to attenuate diabetic cardiomyopathy in rats. Journal of Cellular and Molecular Medicine, 24(2), 1760-1773. http://dx.doi.org/10.1111/jcmm.14870. PMid:31856386.

Ma, D., Fang, Q., Wang, P., Gao, R., Wu, W., Lu, T., Cao, L., Hu, X., \& Wang, J. (2015). Induction of heme oxygenase- 1 by $\mathrm{Na}+-\mathrm{H}+$ exchanger 1 protein plays a crucial role in imatinib-resistant chronic myeloid leukemia cells. The Journal of Biological Chemistry, 290(20), 1255812571. http://dx.doi.org/10.1074/jbc.M114.626960. PMid:25802333.

Moss, H. G., Brown, T. R., Wiest, D. B., \& Jenkins, D. D. (2018). $\mathrm{N}$-Acetylcysteine rapidly replenishes central nervous system glutathione measured via magnetic resonance spectroscopy in human neonates with hypoxic-ischemic encephalopathy. Journal of 
Cerebral Blood Flow and Metabolism, 38(6), 950-958. http://dx.doi. org/10.1177/0271678X18765828. PMid:29561203.

Pagano, D., Oliva, E., Khouzam, S., Tuzzolino, F., Cintorino, D., Li Petri, S., di Francesco, F., Ricotta, C., Bonsignore, P., Tropea, A., Calamia, S., Costanzo, F., Luca, A., \& Gruttadauria, S. (2018). The addition of simvastatin administration to cold storage solution of explanted whole liver grafts for facing ischemia/reperfusion injury in an area with a low rate of deceased donation: a monocentric randomized controlled double-blinded phase 2 study. BMC Surgery, 18(1), 122. http://dx.doi.org/10.1186/s12893-018-0455-7. PMid:30587165.

Peralta, C., Jiménez-Castro, M. B., \& Gracia-Sancho, J. (2013). Hepatic ischemia and reperfusion injury: effects on the liver sinusoidal milieu. Journal of Hepatology, 59(5), 1094-1106. http://dx.doi.org/10.1016/j. jhep.2013.06.017. PMid:23811302.

Rakić, M., Patrlj, L., Amić, F., Aralica, G., \& Grgurević, I. (2018). Comparison of hepatoprotective effect from ischemia-reperfusion injury of remote ischemic preconditioning of the liver vs local ischemic preconditioning of the liver during human liver resections. International Journal of Surgery, 54(Pt A), 248-253. http://dx.doi. org/10.1016/j.ijsu.2018.05.001. PMid:29733995. von Platen, A., D’Souza, M. A., Rooyackers, O., \& Nowak, G. (2021). Intrahepatic Microdialysis for Monitoring of Metabolic Markers to Detect Rejection Early After Liver Transplantation. Transplantation Proceedings, 53(1), 130-135. http://dx.doi.org/10.1016/j. transproceed.2020.02.157. PMid:32631580.

Wang, C., Yuan, W., Hu, A., Lin, J., Xia, Z., Yang, C. F., Li, Y., \& Zhang, Z. (2020). Dexmedetomidine alleviated sepsis-induced myocardial ferroptosis and septic heart injury. Molecular Medicine Reports, 22(1), 175-184. http://dx.doi.org/10.3892/mmr.2020.11114. PMid:32377745.

Xu, L., Yu, Y., Sang, R., Li, J., Ge, B., \& Zhang, X. (2018). Protective Effects of Taraxasterol against Ethanol-Induced Liver Injury by Regulating CYP2E1/Nrf2/HO-1 and NF- $\mathrm{BB}$ Signaling Pathways in Mice. Oxidative Medicine and Cellular Longevity, 2018, 8284107. http://dx.doi.org/10.1155/2018/8284107. PMid:30344887.

Zhang, D., Shen, J., Wang, C., Zhang, X., \& Chen, J. (2009). GSHdependent iNOS and HO-1 mediated apoptosis of human Jurkat cells induced by nickel(II). Environmental Toxicology, 24(4), 404-414. http://dx.doi.org/10.1002/tox.20440. PMid:18830972. 